\title{
ВЗАИМОСВЯЗЬ УРОВНЯ ГЛИКИРОВАННОГО ГЕМОГЛОБИНА С ПОКАЗАТЕЛЯМИ ОЦЕНКИ КАЧЕСТВА ГЛИКЕМИЧЕСКОГО КОНТРОЛЯ У ПАЦИЕНТОВ С САХАРНЫМ ДИАБЕТОМ 1 ТИПА ПО ДАННЫМ ПРОФЕССИОНАЛЬНОГО НЕПРЕРЫВНОГО МОНИТОРИРОВАНИЯ глюкозы
}

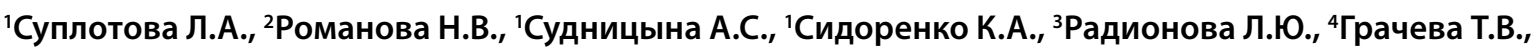 \\ ${ }^{5}$ Плотников Н.В., ${ }^{5}$ Хиева Е.В.
}

\author{
'ФГБОУ ВО «Тюменский государственный медицинский университет» Минздрава России, Тюмень \\ 2ГБУз ТО «Областная клиническая больница №2», Тюмень \\ ${ }^{3}$ БУз ОО «Областная клиническая больнича», Омск \\ 4ГБУз СО «Свердловская областная клиническая больница №1》, Екатеринбург \\ 5ГБУ «Курганская областная клиническая больница», Курган
}

\begin{abstract}
АКТУАЛЬНОСТЬ: непрерывное мониторирование гликемии (НМГ) обеспечивает наиболее полную информацию о характере гликемических экскурсий, позволяет провести интегративную оценку качества гликемического контроля. Согласно рекомендаций Международного консенсуса НМГ 2019г. время нахождения в целевом диапазоне (time in range - TIR), выше целевого диапазона (time above range - TAR) и ниже целевого диапазона (time below range - TBR) являются основными показателями оценки краткосрочного гликемического контроля. Продемонстрировано, что TIR наряду с гликированным гемоглобином ( $\left.\mathrm{HbA}_{1 c}\right)$ ассоциирован с развитием микрососудистых осложнений СД. Однако анализ взаимосвязи значений вне целевого диапазона с уровнем $\mathrm{HbA}_{1 с}$ не проводился.

ЦЕЛЬ: оценить взаимосвязь $\mathrm{HbA}_{1 c}$ с показателями оценки качества гликемического контроля у пациентов с сахарным диабетом 1 типа по данным профессионального НМГ (ПНМГ).

МАТЕРИАЛЫ И МЕТОДЫ: представлены результаты открытого многоцентрового проспективного исследования (Тюмень, Курган, Екатеринбург, Омск) взаимосвязи HbA 1 с TIR, TAR, TBR у пациентов с СД 1 типа в возрасте 18 лет и старше, длительностью заболевания более 1 года, получающих терапию аналоговыми инсулинами (Гларгин 100, Гларгин 300, Деглудек, Детемир, Аспарт, Лизпро, Глулизин). Все обследования проводились после подписания пациентами информированных согласий. ПНМГ выполнено 100 пациентам с использованием устройства iPro2 Medtronic в течение 6 дней. Для оценки углеводного обмена определялся $\mathrm{HbA}_{1 с}$ методом, сертифицированным в соответствии с Национальной программой стандартизации (NGSP). Для анализа показателей TIR, TAR, TBR, глюкозы сенсора использовалась программа CareLink iPro Medtronic. TIR\% был определен как процент времени нахождения в диапазоне значений глюкозы 3,9-10,0 ммоль/л, TBR\% - менее 3,9 ммоль/л, TAR\% - более 10,0 ммоль/л, согласно данным международного консенсуса о времени нахождения в диапазонах. Материалы исследования статистически обработаны с применением программы для работы с электронными таблицами Microsoft Office Excel 2010, а также пакета прикладных программ IBM SPSS Statistics 23 версия.
\end{abstract}

РЕЗУЛЬтАТЫ: обследовано 100 пациентов в возрасте 32 [24;40] лет, 24\% составляли мужчины и 76\% женщины с длительностью заболевания 15 [7;21] лет, с уровнем $\mathrm{HbA}_{1 c} 8,2 \%$ [7,2;9,8], TIR - 56\% [43;71], TAR - 28\% [14;47,5], TBR - 9\% [4;15,5] и глюкозы сенсора 8,0 [6,8;9,4]. При проведении корреляционного анализа отмечаются значимые отрицательные корреляции TIR, TBR и положительная TAR с уровнем $\mathrm{HbA}_{1 \mathrm{c}}$ $(p<0,01)$. Также отмечаются статистически значимые отрицательные корреляции глюкозы сенсора с TIR, TBR и положительные корреляции с TAR $(p<0,01)$.

ВЫВодЫ: продемонстрирована отчетливая взаимосвязь между уровнем HbA1C и показателями времени нахождения в диапазонах. Несмотря на то, что $\mathrm{HbA}_{1 С}$ остается важным предиктором риска осложнений сахарного диабета, показатели TIR, TAR, TBR по результатам HMГ, могут использоваться в качестве дополнительных критериев оценки качественного гликемического контроля.

КЛЮЧЕВЫЕ СЛОВА: сахарный диабет 1 типа; профессиональное непрерывное мониторирование глюкозы; время нахождения в диапазонах; гликированный гемоглобин 